\title{
Effect of Misfit on Preload Maintenance of Retention Screws of Implant-Supported Prostheses
}

\author{
Wirley Gonçalves Assunção, Paulo Henrique dos Santos, Juliana Aparecida Delben, Érica Alves Gomes, \\ Valentim Adelino Ricardo Barão, and Lucas Fernando Tabata
}

(Submitted August 16, 2008)

\begin{abstract}
The aim of this study was to evaluate the effect of unilateral misfit at different levels on a crown-implantretention screw system of implant-supported crowns. Hexagon castable UCLA abutments were cast in Co-Cr alloy to fabricate 48 metallic crowns divided into four groups $(n=12)$. Group A: crowns did not present misfit; Groups B, C and D: crowns were fabricated with unilateral misfit of 50, 100, and $200 \mu \mathrm{m}$, respectively. The crowns were attached by titanium retention screw with $30 \mathrm{~N} / \mathrm{cm}$ to external hexagonal osseointegrated implants embedded in acrylic resin. After $2 \mathrm{~min}$, the retention screw of each replica was submitted to detorque evaluation by an analogic torque gauge. Three retention screws were used to perform detorque evaluation at each replica and the procedure was repeated twice with each screw. Each group was submitted to 72 detorque measurements. Data were evaluated by ANOVA and Tukey test $(P<0.05)$. All groups exhibited significant decrease $(P<0.05)$ in preload and the lowest decrease occurred in Group A. Groups B, C, and D were statistically significant different from Group A $(P<0.05)$, but there was no statistically significant difference between Groups B and D $(P>0.05)$. Crowns with unilateral misfit presented higher preload decrease than crowns completely fitted to osseointegrated implants.
\end{abstract}

Keywords joining, mechanical testing, titanium

\section{Introduction}

The success of implant-supported prostheses depends on the passive fit between components for long-lasting osseointegration of dental implants since the implant-bone anchorage allows only limited movement of $10 \mu \mathrm{m}$ (Ref 1).

There are two categories of complication that occur in implant therapy: biological and mechanical. Biological complications refer to function disturbances due to biological processes that affect supporting tissues (Ref 2). Mechanical failures include screw loosening that is the most common reported complication, especially in single units in premolar and molar areas (Ref 3). Because external loads always amplify dynamic changes in screw joints, misfits and pre-existing deformation within the components will further enhance screw loosening (Ref 4, 5). The level of static stresses caused by misfit depends on size, shape, and location of gaps; interabutment distance; and shape, dimensions, and stiffness of the metal of components. So, horizontal and angular misfit allows

Wirley Gonçalves Assunção, Paulo Henrique dosSantos, Juliana Aparecida Delben, Érica Alves Gomes, Valentim Adelino Ricardo Barão, and Lucas Fernando Tabata, Department of Dental Materials and Prosthodontics, Araçatuba Dental School, São Paulo State University (UNESP), José Bonifácio, 1193, Araçatuba, SP CEP 16015-050, Brazil. Contact e-mails: wirley@foa.unesp.br, paulosantos@ foa.unesp.br, ju.delben@hotmail.com, ericaagomes@yahoo.com.br, ricardo.barao@hotmail.com and lftabata@hotmail.com. bending of screws and bending stress in implant components (Ref 6).

The stability of implant/abutment connection and propensity for screw loosening is also influenced by preload (Ref 7). Preload is the initial load in tension on the screw and results in the clamping force that keeps the components together (Ref 8). The screw loosens only if external forces attempting to disengage the parts are greater than the force keeping them together (Ref 9). The matting surfaces of components also influence the joint stability. After tightening, the microroughness of metal-contacting surfaces flattens and the microscopic distance between parts decreases. Consequently, preload and clamping force are also reduced (Ref 7, 10, 11).

To date, no precise method for determining the accuracy of fit of an implant superstructure exists, and the term passive fit has not yet been accurately defined biomechanically. It is also not yet been established a clinical acceptable level of misfit that does not adversely affect the implant bone and whether passive fit is an essential prerequisite for long-lasting osseointegration (Ref 1, 12).

So, the aim of this in vitro study was to evaluate the effect of different levels of unilateral angular misfit on preload maintenance of titanium retention screws of single unit implantsupported prosthesis.

\section{Experimental Procedure}

Forty-eight hexagon castable plastic UCLA abutments (EUCLA 406, SIN, Implant System, São Paulo, SP, Brazil) were cast in cobalt-chromium (Co-Cr) alloy to obtain metallic crowns. Twelve abutments presented passive fit to implants while the remaining 36 abutments presented unilateral angular 


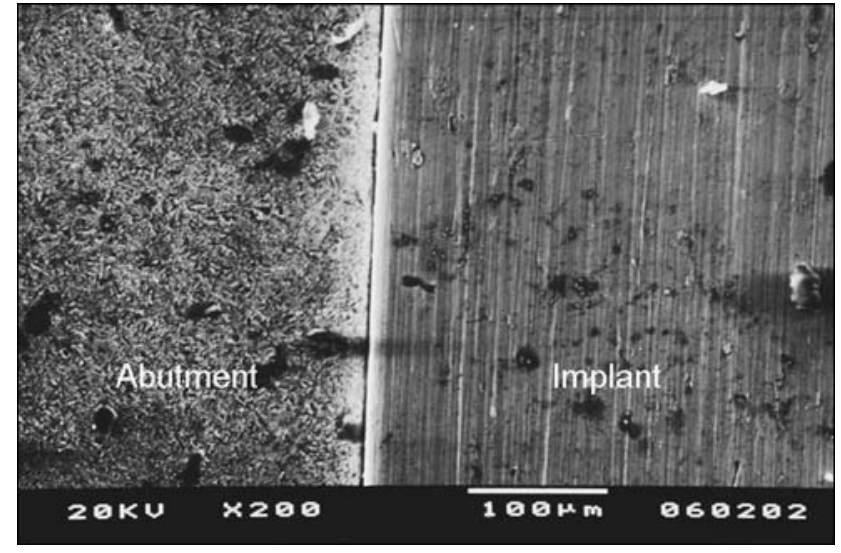

Fig. 1 SEM of implant-abutment interface with passive fit (Group A)

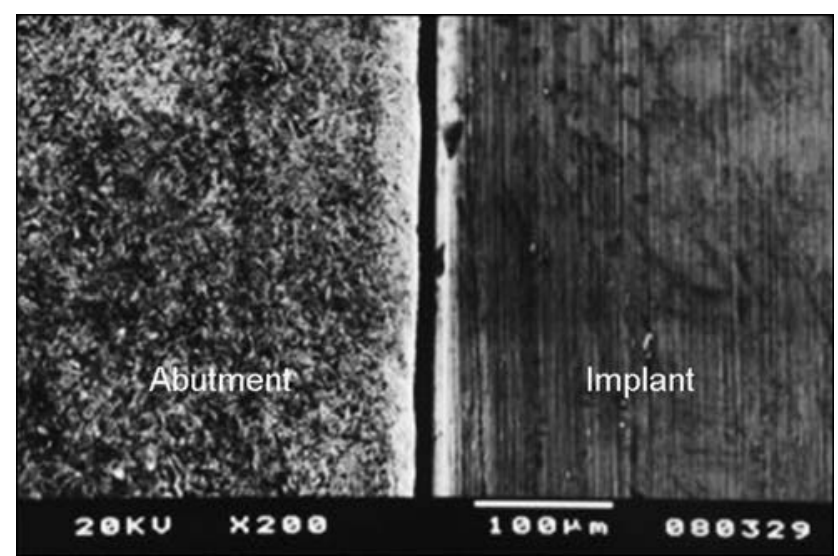

Fig. 2 SEM of implant-abutment interface with misfit of $50 \mu \mathrm{m}$ (Group B)

misfit of $50 \mu \mathrm{m}( \pm 8 \mu \mathrm{m}), 100 \mu \mathrm{m}( \pm 8 \mu \mathrm{m})$, and $200 \mu \mathrm{m}$ $( \pm 8 \mu \mathrm{m})$.

The abutments were waxed in conical design with autopolymerizing acrylic resin (Duralay, Reliance Dental Mfg. Co., Worth, IL, USA) with $8 \mathrm{~mm}$ in high and $8 \mathrm{~mm}$ in the major diameter (Ref 8).

The abutments were invested in a phosphate-bonded investment (Flash, CNG Prosthetic Solutions Ltd., São Paulo, SP, Brazil) and cast with a Co-Cr alloy (StarLoy C, DeguDent $\mathrm{GmbH}$, Rodenbacher Chaussee 4, Wolfgang, Germany). After casting, specimens were allowed to bench cool and airborne particle abraded using 60- $\mu \mathrm{m}$ aluminum oxide (Bio-Art Dentistry Equipments Ltd., São Carlos, SP, Brazil) with 75 lbs pressure.

The 48 metallic crowns were divided into four groups $(n=12)$ according to misfit level: Group A: crowns with passive fit, Group B: crowns with unilateral angular misfit of $50 \mu \mathrm{m}$, Group C: crowns with unilateral angular misfit of $100 \mu \mathrm{m}$, and Group D: crowns with unilateral angular misfit of $200 \mu \mathrm{m}$. Figures 1, 2, 3, and 4 show the implant-abutment interface through scanning electronic microscopy (SEM) for Groups A, B, C, and D, respectively.

Forty-eight external hexagon implants with $3.75 \mathrm{~mm}$ in diameter and $15.0 \mathrm{~mm}$ in length (Revolution SUR 4015, SIN,

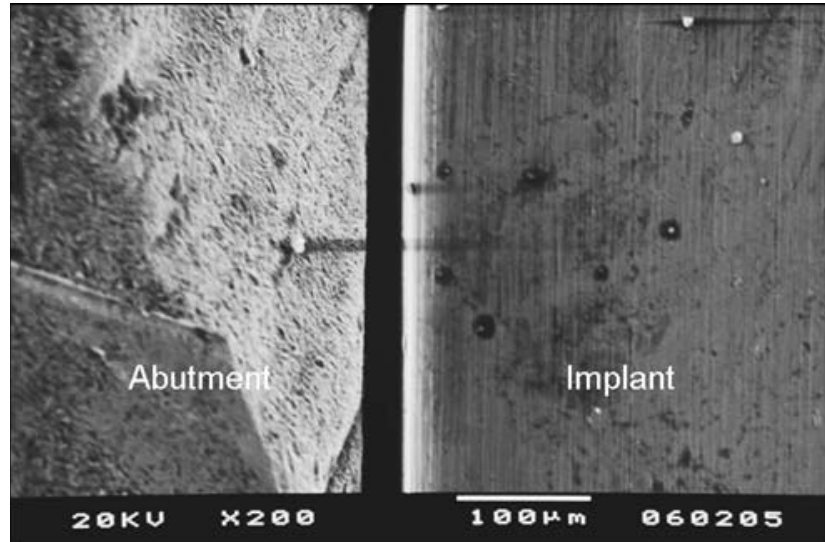

Fig. 3 SEM of implant-abutment interface with misfit of $100 \mu \mathrm{m}$ (Group C)

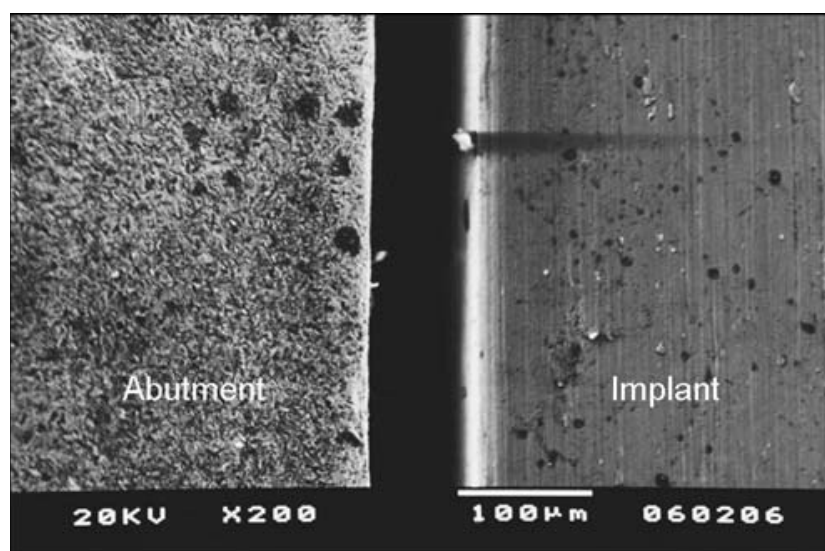

Fig. 4 SEM of implant-abutment interface with misfit of $200 \mu \mathrm{m}$ (Group D)

Implant System, São Paulo, SP, Brazil) were embedded with autopolymerizing acrylic resin (JET-Classico Dentistry Products, São Paulo, SP, Brazil) characterizing the implant/crown assembly.

Each implant/crown assembly was positioned in a holding device and titanium screw (PTQ 2008, SIN, Implant System, São Paulo, SP, Brazil) was tightened to $30 \pm 0.5 \mathrm{~N} \mathrm{~cm}$ according to manufacturer's instruction using a calibrated torque gauge (BTG36CN-S, Tohnichi Mfg. Co. Ltd., Tokyo, Japan). After $2 \mathrm{~min}$, the screw was loosened and the torque required to loosen the screw (detorque) was recorded. Three titanium screws were submitted to detorque evaluation in each implant/crown assembly. The procedure of detorque measurement was repeated twice for each screw, totalizing six detorque measurements for each sample.

Group means were compared by one-way analysis of variance (ANOVA) and Tukey test $(\alpha=0.05)$.

\section{Results}

Table 1 shows the means of detorque values obtained after the measurements of the three titanium screws in each sample for all groups. 
Table 1 Means and standard deviation (SD) of detorque values of each sample in each group

\begin{tabular}{llccc}
\hline Sample & Group A & Group B & Group C & Group D \\
\hline 1 & 25.58 & 25.25 & 20.75 & 24.42 \\
2 & 25.5 & 23.42 & 22.92 & 24.17 \\
3 & 25.5 & 24.42 & 19.25 & 23.00 \\
4 & 25.42 & 22.83 & 22.83 & 23.46 \\
5 & 24.5 & 23.00 & 22.5 & 23.75 \\
6 & 25.42 & 24.50 & 23.33 & 24.17 \\
7 & 25.33 & 24.42 & 22.00 & 24.00 \\
8 & 25.17 & 24.08 & 23.50 & 24.42 \\
9 & 25.00 & 24.67 & 24.00 & 23.83 \\
10 & 23.88 & 22.25 & 22.42 & 21.25 \\
11 & 25.17 & 22.08 & 22.22 & 25.58 \\
12 & 25.67 & 22.30 & 23.92 & 24.00 \\
Mean & 25.18 & 23.60 & 22.47 & 23.84 \\
SD & 0.52 & 1.09 & 1.35 & 1.02 \\
\hline
\end{tabular}

Table 2 ANOVA for means of detorque values for all groups

\begin{tabular}{lccccc}
\hline Source & df & SS & MS & $\boldsymbol{F}$ & $\boldsymbol{P}$ value \\
\hline Group & 4 & 416.85 & 104.21 & 120.13 & 0.00001 \\
Error & 55 & 47.71 & 0.87 & & \\
Total & 59 & 464.57 & & &
\end{tabular}

df, Degrees of freedom; SS, sum of squares; MS, mean square

Table 3 Tukey test for means $(\mathrm{N} \mathbf{~ c m})$ of detorque values of Groups A, B, C, and D and the reference torque value

\begin{tabular}{lll}
\hline Source & Means & $\mathbf{5 \%}$ \\
\hline Reference torque value & 30.00 & $\mathrm{a}$ \\
Group A & 25.18 & $\mathrm{~b}$ \\
Group D & 23.84 & $\mathrm{c}$ \\
Group B & 23.60 & $\mathrm{c}$ \\
Group C & 22.47 & $\mathrm{~d}$
\end{tabular}

*Means followed by different letters are statistically different $(P<0.05)$

One-way ANOVA revealed statistically significant difference $(P=0.00001)$ among groups (Table 2). According to Tukey test, all groups (A, B, C, and D) presented a significantly lower torque value $(P<0.05)$ in comparison to reference torque value applied initially $(30 \pm 0.5 \mathrm{~N} \mathrm{~cm})$. Numerically, Group A exhibited closer mean to reference torque value. Means of Groups B, C, and D were statistically different from that of Group A $(P<0.05)$. However, there was no statistically significant difference between the means of Groups B and D (Table 3).

\section{Discussion}

Preload is the force developed within the screw by the application of a tightening torque. The application of preload generates an overall clamping force between the parts of the implant system. So, the stability of screw joint is directly related to the preload achieved from the tightening torque and maintenance of this preload over time (Ref 13). If the screw loosens and preload force falls below a critical level, joint stability may be compromised (Ref 9).

The difference between the group with passive fit (Group A) and the groups with unilateral angular misfit (Groups B, C, and D) suggests that misfit between crown and implant influences preload maintenance of retention screws in UCLA abutments, which is in agreement with other studies (Ref 9, 14, 15). Binon (Ref 4), and Binon and McHugh (Ref 8) stated that fit between components results in a more resistant screw joint to screw loosening. The study of Millington and Leung (Ref 6) demonstrated that horizontal and angular misfits from 55 to $104 \mu \mathrm{m}$ in screw joints result in flexural stress in implant components and allow screw loosening.

According to Burguete et al. (Ref 16), when a prosthesis does not make complete contact with an abutment, there will be a gap between all or part of the mating surfaces. If there is no contact, the preload is used to bring the mating surfaces closer together, which makes the screw vulnerable to fatigue fractures and loosening (Ref 6). Therefore, no fatigue protection is obtained since any external load applied to separate the prosthesis from the abutment causes further tension in the screw and is not dissipated by relieving compressive stresses in the clamped parts.

The mating surfaces between components also influence preload maintenance of retention screws since microroughness increases the microscopic distance between contacting surfaces (Ref 11). So, the clamping force that keeps the components together decreases, which results in a lower torque value following screw tightening than the insertion torque value (Ref 7).

In addition, the torque applied to tighten the abutment/ implant interface is distributed in friction between screw head and abutment, and threads on the screw and implant. The initial contact occurs only between microscopically rough high spots of screw and implant threads. Consequently, creep and flow of components result in a reduction of preload know as embedment relaxation. This relaxation allows $2-10 \%$ reduction in preload within the first few seconds or minutes (Ref 17).

In the present study, results showed a decrease in preload of titanium screws from 16.1 to $25.1 \%$ depending on the misfit level between crown and implant. However, these findings are in disagreement with Breeding et al. (Ref 17), since other factors as screw materials, composition, manufacturer quality control, screw design, and insertion torque may influence preload maintenance (Ref 11).

Kano et al. (Ref 7) compared the detorque values among machined titanium abutments, premachined palladium abutments cast with palladium, plastic abutments cast with nickelchromium, and plastic abutments cast with cobalt-chromium. The preload maintenance for the group of plastic abutments cast with cobalt-chromium $(84.0 \pm 7 \%)$ was similar to that exhibited for Group A $(83.9 \%)$ in the present study.

Premachined cobalt-chromium abutments with plastic sleeve were evaluated in this study since Weinberg (Ref 15$)$ suggested that castable abutments are more technically sensible to casting procedure. Byrne et al. (Ref 5) also demonstrated that plastic abutments cast in gold-palladium alloy presented vertical misfit of $141 \mu \mathrm{m}$.

However, although premachined abutments were used, there was significant preload decrease in all groups independently of 
extrinsic factors. The casting procedure may have influenced preload maintenance since it can damage the integrity of screw joint (Ref 18). Kano et al. (Ref 19) also demonstrated that casting procedure may affect rotational fit between crown and implant with greater misfit for abutments cast in cobaltchromium alloy.

\section{Conclusions}

Within the limitations of this study, the following conclusions were drawn:

(1) All groups exhibited significant preload decrease $(P<.05)$ with lower decrease for Group A.

(2) In general, the unilateral angular misfit influenced preload maintenance and greater misfits generated greater preload decrease.

\section{References}

1. S.M. Heckmann, M. Karl, M.G. Wichmann, W. Winter, F. Graef, and T.D. Taylor, Cement Fixation and Screw Retention: Parameters of Passive Fit an In Vitro Study of Three-Unit Implant-Supported Fixed Partial Dentures, Clin. Oral Impant. Res., 2004, 15(4), p 466-473

2. T. Berglundh, L. Persson, and B. Klinge, A Systematic Review of the Incidence of Biological and Technical Complications in Implant Dentistry Reported in Prospective Longitudinal Studies of At Least 5 Years, J. Clin. Periodontol., 2002, 29(Suppl 3), p 197-212

3. W. Becker and B.E. Becker, Replacement of Maxillary and Mandibular Molars with Single Endosseous Implant Restorations: A Retrospective Study, J. Prosthet. Dent., 1995, 74(1), p 51-55

4. P.P. Binon, The Effect of Implant/Abutment Hexagonal Misfit on Screw Joint Stability, Int. J. Prosthodont., 1996, 9(2), p 149-160

5. D. Byrne, F. Houston, R. Cleary, and N. Claffey, The Fit of Cast and Premachined Implant Abutments, J. Prosthet. Dent., 1998, 80(2), p 184-192
6. N.D. Millington and T. Leung, Inaccurate Fit of Implant Superstructures. Part I: Stresses Generated on the Superstructure Relative to the Size of Fit Discrepancy, Int. J. Prosthodont., 1995, 8(6), p $511-516$

7. S.C. Kano, P. Binon, G. Bonfante, and D.A. Curtis, Effect of Casting Procedures on Screw Loosening in UCLA-Type Abutments, J. Prosthodont., 2006, 15(2), p 77-81

8. P.P. Binon and M.J. Mchugh, The Effect of Eliminating Implant/ Abutment Rotational Misfit on Screw Joint Stability, Int. J. Prosthodont., 1996, 9(6), p 511-519

9. I. Alkan, A. Sertgöz, and B. Ekici, Influence of Occlusal Forces on Stress Distribution in Preloaded Dental Implant Screws, J. Prosthet. Dent., 2004, 92(4), p 319-325

10. L.C. Breeding, D.L. Dixon, E.W. Nelson, and J.D. Tietge, Torque Required to Loosen Single-Tooth Implant Abutment Screws Before and After Simulated Function, Int. J. Prosthodont., 1993, 6(5), p 435439

11. L. Jöurneus, T. Jemt, and L. Carlsson, Loads and Designs of Screw Joints for Single Crows Supported by Osseointegrated Implants, Int. J. Oral Maxillofac. Implant., 1992, 7(3), p 353-359

12. T.D. Taylor and J.R. Agar, Twenty Years of Progress in Implant Prosthodontics, J. Prosthet. Dent., 2002, 88(1), p 89-95

13. D.G. Gratton, S.A. Aquilino, and C.M. Stanford, Micromotion and Dynamic Fatigue Properties of the Dental Implant-Abutment Interface, J. Prosthet. Dent., 2001, 85(1), p 47-52

14. P.P. Binon, Implants and Components: Entering the New Millennium, Int. J. Oral Maxillofac. Implant., 2000, 15(1), p 76-94

15. L.A. Weinberg, The Biomechanics of Force Distribution in ImplantSupported Prostheses, Int. J. Oral Maxillofac. Implant., 1993, 8(1), p 19-31

16. R.L. Burguete, R.B. Johns, T. King, and E.A. Patterson, Tightening Characteristics for Screwed Joints in Osseointegrated Dental Implants, J. Prosthet. Dent., 1994, 71(6), p 592-599

17. L.C. Breeding, D.L. Dixon, E.W. Nelson, and J.D. Tietge, Torque Required to Loosen Single-Tooth Implant Abutment Screws Before and After Simulated Function, Int. J. Prosthodont., 1993, 6(5), p 435439

18. A.B. Carr, J.B. Brunski, and E. Hurley, Effects of Fabrication, Finishing, and Polishing Procedures on Preload in Prostheses Using Conventional Gold and Plastic Cylinders, Int. J. Oral Maxillofac. Implant., 1996, 11(5), p 589-598

19. S.C. Kano, P. Binon, G. Bonfante, and D.A. Curtis, The Effect of Casting Procedures on Rotational Misfit in Castable Abutments, Int. J. Oral Maxillofac. Implant., 2007, 22(4), p 575-579 